\title{
Research on the Practical Teaching of Data Structures and Algorithms Course
}

\author{
Hongli Chen*, Li Zhang, Bo Liu, Xudong Liu \\ Faculty of Information Technology, Beijing University of Technology, Beijing 100124, China \\ *Corresponding author: Hongli Chen, chenhongli@bjut.edu.cn
}

\begin{abstract}
The success or failure of practical teaching in data structures and algorithms course determines the success or failure of the course group. The reform of practical teaching in this course takes the course group as the background and aims to meet the needs of students at different levels. It proposes a hierarchical practical teaching mode involving three levels in terms of foundation, design, and synthesis driven by cases throughout the whole course group and a fine process control mechanism based on multi-stage process assessment.
\end{abstract}

Keywords: Curriculum group; Hierarchical practical teaching; Process assessment

Publication date: July 2021; Online publication: July 30, 2021

\section{Introduction}

Curriculum group is a type of curriculum construction mode corresponding to a single course, guided by modern education. This chain-type curriculum group with reasonable structure, mutual connection, mutual coordination, and mutual reference is composed of related courses that influence each other in the teaching plan in forming a complete teaching content system ${ }^{[1]}$. The course group of software development for information specialty in general colleges and universities can be divided into professional basic courses and software development courses. C programming language, data structure and algorithm, operating system, database principle, etc. belong to the category of professional basic courses. Object-oriented programming, web programming, software engineering, Java programming, algorithm design and analysis, mobile application development, system analysis and modeling technology, software testing technology, etc. are courses that are not only independent of each other but also related to each other in this group. In the horizontal aspect, there is an internal logical connection while in the vertical direction, there is a connecting relationship. The emphasis of each course is different, but they are around the main line of software design, development, and testing. The training subjects are undergraduates majoring in software engineering, computer science and technology, as well as other related majors. Among them, the data structures and algorithms course which is a very practical course plays a connecting role in the whole course group. The success or failure of its practical teaching is directly related to the success or failure of the whole course group.

\section{Current situation of the practical teaching of data structures and algorithms course}

\subsection{Poorly mastered pilot courses and difficulty in practice}

In the teaching plan of colleges and universities, $\mathrm{C}++$ programming is generally arranged in the second semester whereas data structures and algorithms course is arranged in the third semester. Although the general teaching plan arranges these two courses in adjacent semesters, most of the knowledge gained from $\mathrm{C}++$ related pilot courses would be forgotten after the holidays which causes the in-class experiments and 
practice of data structures and algorithms course to be difficult in addition to the inability to achieve excellent results.

\subsection{Non-applicability of the isolated and single practical teaching in the course group}

At present, the practical teaching of this course is isolated and single. A single practical teaching cannot meet the needs of students with different programming levels which makes students lose interest in learning. The isolated practical teaching does not organically combine the courses in the program development course group; hence, it is difficult to stimulate students' interest in the next stage of learning, and greatly affects the teaching effect of the course group.

\subsection{Non-suitability of traditional examinations due to the lack of fine process control}

The data structures and algorithms course is used to guide programming. Hence, for a practical problem, the ability of abstract analysis is reflected by the advantages and disadvantages of writing code. The current curriculum assessment is mainly based on paper results where it has been found that many students who are not able to write code have excellent curriculum assessment results. In addition, in the process of teaching, there is no control in the process of students and clear ideas for each link. Hence, it is not possible to ensure the successful completion of teaching.

As the most important part of the course group, there is a need to focus on the problems existing in the practical teaching of the course in addition to carrying out reform in the arrangement of the content as well as the control and assessment of the practical teaching in order to ensure the smooth progress of the software development course group.

\section{Reform measures of practical teaching}

\subsection{Case driven hierarchical practical teaching mode throughout the course group}

The software development course group emphasizes integration construction, considers the curriculum as the surface while knowledge as the point and pays attention to curriculum knowledge reorganization as well as knowledge fusion. By clarifying the logical relationship of curriculum knowledge, organizing the teaching content reasonably, highlighting the key points of the curriculum on the basis of avoiding repetition of content, making the curriculum system coherent, integrating the content, and cooperating with each other play roles in making inferences and promoting each other. There is a need to regularly review and update the teaching content so that it is able to keep up with the forefront of the discipline and keep pace with the times. On the one hand, some contents need to be eliminated. For example, $\mathrm{C}++$ and Java programming are both object-oriented programming languages. In terms of the key technology of objectoriented programming (abstraction, class, inheritance and polymorphism) which is a repeated knowledge in these two courses, the teaching of this content should be emphasized in $\mathrm{C}++$ while being reduced during the teaching of Java programming by leaving it to students to self-study and allowing them to digest and absorb it in practical projects. In this way, the teaching of Java programming can be focused on visual programming, multithreading programming, network programming, database programming, and the design pattern of Java. On the other hand, the proper planning and repetition of key contents are conducive to master knowledge. Many of the repeated learning points are the basis of knowledge transfer. Therefore, in achieving the teaching objectives of the course group, there is a need to eliminate large areas of repetition yet encouraging the appropriate reproduction design of the same knowledge content from different angles rather than self-learning. This is more conducive to students to master the knowledge contents.

The courses in the course group are highly practical and engineering which emphasize on hands-on and practice to solve problems. The theoretical and practical aspects of software development courses are interrelated, so it is difficult for students to learn to develop real software just by listening to their theories. 
There is a need to experience and master the idea of software development through hands-on and real practice. The traditional teaching in software development courses focuses on theory while it neglects the practical aspects. "Learning" and "using" are out of touch; hence, students lack motivation and interest in learning. Case teaching method is an appropriate method in the teaching of software development courses. It is conducive to cultivate students' interest in learning, initiative, and practical skills. Case teaching method is extremely consistent with the strong practical requirements of software development courses especially the introduction of complex engineering cases; hence, it is more conducive to improve the teaching effect of software development courses.

As for the teaching mode of the courses within the course group ${ }^{[3]}$, the "Trinity Teaching Mode" of classroom teaching, case driven, inspired interaction, and innovative practice is adopted. Many language courses can be taught in the computer room and can be practiced through speaking. The active teaching method and student training of "case driven teaching" and "learning by doing" are adhered to.

In the selection of practical cases for teaching, the principle is to cover as many knowledge points as possible, being close to actual projects of enterprises, having certain comprehensiveness, and at moderate levels of difficulty so that students are familiar with the application field of these projects. Curriculum design topics and graduation topics can be decided by the curriculum group leader and school enterprise cooperation unit. Many years of teaching practice have shown that for different knowledge points or different subjects in the same course, those who choose a case will choose the same case again. In this way, the teaching effect is better, and students can understand the significance of learning each knowledge point or different subjects in the same course. For example, in the teaching of $\mathrm{C}$ and $\mathrm{C}++$, the library management system used in the school is selected. In the process of learning $\mathrm{C}$ language, students are required to use the process-oriented programming method to develop the system. On the other hand, in the process of learning $\mathrm{C}++$, students are required to use the object-oriented programming method to develop the system again. Through the comparison of different programming methods for the same system, students would realize the fundamental differences, advantages, and disadvantages of process-oriented and objectoriented programming. In the teaching of the courses in the advanced stage, the system can be used continuously. For example, in the teaching of software engineering, the system should be used so that students can complete the information of each stage according to the standardized development process for the parts that have not been standardized in the previous development process. This whole process would help students find the significance of normative theoretical guidance.

Literatures ${ }^{[2]}$ have pointed out that the cultivation of students' ability is a process of gradual formation, comprehensive effect, and a spiral rise which is not a simple straight-line improvement, but a spiral rise process from basic skills to practical ability, from practical ability to innovation ability, and finally from innovation ability to comprehensive ability. Hence, the practical content should be formed from shallow to deep, from point to surface, and from simple to complex in order for students to develop from mastering basic skills, having hands-on ability and practical ability, having innovation ability, and to finally form the ability to solve complex engineering problems. While designing specific cases according to the knowledge content, the principle of understanding the "classic" knowledge to "reality" satisfaction, and then to "future" prediction. In other words, in the course group, it is necessary for students to first, fully understand and master the knowledge points of each course, then solve practical problems according to actual situations, that is, the "reality" satisfaction, and finally achieving "future" prediction, that is, to achieve the teaching objectives of the course group. In this way, students' ability to solve complex engineering problems would gradually improve.

Due to the differences in students' practical skills, the goal of the reform is on how to carry out targeted practical training for students at different levels that does not only meet the needs of different students but also responds to the priority courses in the course group as well as to stimulate their interest in the follow- 
up courses. The hierarchical practical teaching mode is adopted to put forward different requirements for students with different knowledge base and programming skills. The practical teaching of the course takes a case throughout the course group as the main line and cultivates the practical ability from three levels in terms of foundation, design, and synthesis in order to improve their practical and innovation ability in addition to the ability to solve complex engineering problems and team cooperation.

Using data structure course teaching as an example:

\subsubsection{Case design}

Case design is the core of practical teaching reform in the construction of course group. Firstly, specific case design and task decomposition are carried out under the background of the course group, and then they are implemented within the specific course so that some specific cases that meet the actual needs can be obtained. Some courses in the course group can set up various innovation training in the innovation link according to the specific background of the case as well as analyze and design from the perspective of users and technology, respectively in order to acquire innovative design schemes that would lead the future demands and further improve user experience. Here, the role of students would change, and clear guidance is needed. Reflected in the context of complex engineering cases, they not only train and implement executive ability but also lead to innovation appropriately.

In view of the data structure course teaching, the library management system is taken as a case to run through the whole course group. The corresponding knowledge points of the library management system in data structure course are shown in Table 1. The case is divided into five sub modules which are library information management, reader information management, input temporary storage, book classification management, and book borrowing management. The library information management module includes the functions of input, deletion, query, and modification of books. The query of books is the most frequently used function of the system, so it is expressed in the order of linear table. The input, deletion, query, and modification of book information correspond to the operation of linear table. The module also needs to add sorting algorithm to speed up the query speed. The reader information management module includes the functions of inputting, deleting, querying, and modifying the reader information. The realization of these functions involves the chain representation of a linear list and related operations. The input temporary storage module is to store data temporarily in the queue when the book information and reader information are the input which are then converted into sequential or chain representation of linear tables. Book classification management module includes the input, deletion, query, and modification of Chinese book classification information. Chinese book classification is a typical tree structure which involves tree operations. Book borrowing management module stores the borrowing relationship between the readers and the books which involves a many-to-many graph structure. This module involves graph-related operations ${ }^{[2]}$.

Table 1. Case decomposition of the library management system

\begin{tabular}{ccc}
\hline Submodule serial number & Sub module function & Corresponding knowledge points \\
\hline 1 & Library information management & Linear table (sequential representation) \\
2 & Reader information management & Linear list (chain representation) \\
3 & Input temporary storage & Queue \\
4 & Book classification management & Tree \\
5 & Book borrowing management & Graph \\
\hline
\end{tabular}




\subsubsection{Layered practice}

The degree of difficulty of the three levels of practice is different where the practice content, teaching methods, and assessment methods are also different. The specific design is shown in Table 2.

Table 2. Hierarchical practical teaching design

\begin{tabular}{|c|c|c|c|}
\hline Practice type & Practice content & Teaching methods & Mastery \\
\hline Basic practice & $\begin{array}{l}\text { Linear table, stack, queue, strings and } \\
\text { arrays, tree, graph, and other data structures } \\
\text { and related operations, query, and sorting } \\
\text { algorithm }\end{array}$ & $\begin{array}{l}\text { In the form of course assignment, } \\
\text { students are required to complete it } \\
\text { within a specified time }\end{array}$ & Must master \\
\hline Design practice & $\begin{array}{l}\text { Book information management, reader } \\
\text { information management, input temporary } \\
\text { storage, book classification management, } \\
\text { book borrowing management }\end{array}$ & $\begin{array}{l}\text { Students are required to complete the } \\
\text { experiment independently, in class, and } \\
\text { under the guidance of teachers }\end{array}$ & Master \\
\hline $\begin{array}{l}\text { Comprehensive } \\
\text { practice }\end{array}$ & $\begin{array}{l}\text { Main program design, optimization of each } \\
\text { module }\end{array}$ & $\begin{array}{l}\text { In groups and teachers would answer } \\
\text { questions }\end{array}$ & General mastery \\
\hline
\end{tabular}

The basic practice is distributed in the form of course assignment and it is to be completed during spare time which fully mobilize students' learning autonomy and cultivate their basic programming skills so as to lay a good foundation for subsequent practice. In order to achieve practice effect, students are required to prepare before classes and submit practical reports after them which aim to cultivate students' independent thinking and practical skills. Comprehensive practice is carried out in groups through mutual help, exchanges, and access to information which provides scheme design and specific implementation, good training for team cooperation, and project practice ability. Teachers can set some challenging and innovative topics based on their own work experiences or scientific research projects. The purpose of this kind of work is to cultivate students' self-learning ability, their ability to analyze and solve practical problems, team spirit, as well as their innovative spirit.

There is a need to synchronously strengthen the experiment link, basic experiment, and classroom teaching content. In view of class experiments, homework, comprehensive training, and other links, the class teaching and programming training hours can reach 1:1 by increasing the time of experimental analysis class and reducing the time of grammar teaching. Students' programming training should follow the approach of "imitation, rewriting, and writing" in addition to stimulating students' programming interest and sense of achievement through program tracking, program error correction, free design, and other types of training. Through the experiment, students would play the initiative, put forward and actively explore their own ideas so as to better grasp knowledge, cultivate their ability of combining theory with practice, as well as their innovation skills.

The corresponding knowledge points of the library management system in $\mathrm{C}$ or $\mathrm{C}++$ courses are shown in Table 3. In $\mathrm{C}$ or $\mathrm{C}++$ courses, this case is used in order for students to complete the library information management module and reader information management module. 
Table 3. Decomposition of the library management system module in $\mathrm{C}$ course

\begin{tabular}{cll}
\hline Functional module & Main knowledge points involved in data structure & \multicolumn{1}{c}{ Main knowledge points involved in C } \\
\hline $\begin{array}{c}\text { Library information } \\
\text { management }\end{array}$ & $\begin{array}{l}\text { The creation, insertion, modification, deletion, Array, dynamic array, search, sort, and file } \\
\text { search, and sorting of linear tables represented by } \\
\text { order }\end{array}$ & $\begin{array}{l}\text { operation } \\
\text { Reader information } \\
\text { management }\end{array}$ \\
\hline
\end{tabular}

In the teaching process of a certain course in the course group, the "Trinity Teaching Mode" which includes "classroom teaching, case driven, enlightening interaction, and innovative practice" is established in addition to the adherence to the active teaching method and student training of "case-driven teaching" and "learning by doing." For example, in the C language learning process, a case runs through the learning process of the whole course which is very important for students. Common cases are shown in Table 4.

Table 4. Case design content in $\mathrm{C}$ language course

\begin{tabular}{cl}
\hline Main knowledge points & \\
\hline Branching structure & Simple guessing game \\
& Step by step programming - guessing game \\
Cyclic structure & Using three kinds of loop statements to realize the problem of 1 to 100 accumulation and summation \\
& Implementation of Fibonacci sequence with for statement \\
Function & Using recursive function to realize the summation problem of 1 to 100 accumulation \\
& Realization of Fibonacci sequence with function and recursive function \\
& Realization of Fibonacci sequence with one dimensional array \\
& Using one-dimensional array and two-dimensional array to realize simple student achievement \\
& management system \\
& Realization of student achievement management system with linked list \\
Pointer & Two-dimensional array and pointer array are used to sort the names of participating countries in \\
& the Olympic Games \\
& Student achievement management system based on structure array
\end{tabular}

It can be seen from the table that simple student achievement management system can be used as cases in one-dimensional array, two-dimensional array, structure array, and linked list. Students' ability would gradually improve when they realize the system with different knowledge points.

Finally, for the comprehensive practice of each course in the course group, in view of the course design content of relevant courses and the final graduation design topic, enterprise experts and front-line teachers can jointly form a teaching reform team to select common complex engineering problems as topics to regularly review and update teaching contents. In this way, the teaching contents would be able to keep up with the frontier of subject development, keep pace with the times, and gradually improve students' innovation ability as well as their ability to solve complex engineering problems in the process of comprehensive practice, curriculum design, and graduation design.

\subsection{Paying attention to the process of assessment and taking ability as the goal of multidimensional assessment}

The selection and determination of assessment methods for a course or teaching link should follow three 
principles which are effectiveness, diversity, and feasibility ${ }^{[4]}$. In the course group, each course is important whereby its success or failure directly affects the next course or even several courses which ultimately determines the success or failure of the whole course group. Therefore, it is very important to establish an effective assessment system. The process assessment emphasizes supervision in the learning process. The assessment in each stage of the process monitoring provides a list of key students for teachers to ensure the smooth progress of the course.

Taking the data structure course as an example, the key to improve the teaching effect and quality if to carry out multi-dimensional assessment of students' learning process. The evaluation subjects here include enterprise experts, group members, instructors, and students. For the evaluation and assessment of data structure course, the instructor can divide it into three parts which are usual performance, final theoretical examination, as well as experimental assessment, and finally determine the weighted course score. Usually, students' performance is mainly evaluated in classes and through computer experiments. The final theoretical examination focuses on students' mastery of key and difficult contents in the course. The experimental assessment mainly assesses the students' practical ability and application innovation ability which can be assessed through the completion of experiments whether the experimental results are correct, the algorithm is feasible, as well as the explanation of the experimental process on-site.

Considering the practicality of data structure, this course focuses on students' practical and innovation ability in the process of practical teaching. Engineers with strong engineering ability in enterprises should be invited to participate in the assessment and evaluation of teaching and related practical courses so that the cultivation of students' practical ability can better meet the requirements of industrial enterprises. In order to avoid the phenomenon of "students go slow and relying too much on students with better ability," the team members' mutual evaluation and students' self-evaluation are added to the evaluation in order for the practical evaluation to be more fair and objective. For example, the weight can be set as follows: Experimental examination score $=$ verification experiment $(20 \%)+$ design experiment $(50 \%)+$ comprehensive experiment (30\%). The assessment results of the curriculum design include comprehensive report $(20 \%)$, on-site defense (30\%), program demonstration (30\%), and group mutual evaluation (20\%). In this way, the assessment not only emphasizes the students' usual learning process, but it also tests the students' understanding of the knowledge points in the course. More importantly, it tests the students' application and innovation ability of the course.

\section{Reform effect}

After a few years of teaching reform, the attendance rate has reached $99 \%$ in data structures and algorithms course. At the same time, students actively think and answer their teachers' questions in a lively atmosphere. Students' learning autonomy has significantly improved in addition to actively complete their extracurricular basic practical homework, prepare design practice, and comprehensive practical homework. Random interviews eliminated the phenomenon of homework plagiarism. The proportion of students with more than 80 points in practice increased from $60 \%$ to $80 \%$ and the proportion of students with more than 80 points in total evaluation increased from $45 \%$ to $70 \%$. Now, most students have changed from their fear of programming to loving programming.

\section{Conclusion}

The data structures and algorithms course is a very practical course, and it is also a connecting course in the software development course group. The success or failure of its practical teaching directly determines the success or failure of the whole course group. The case design throughout the whole course group not only echoes the previous courses but it also leads to the follow-up courses which are closely linked and are 
able to stimulate students' interest in learning for a long time. The hierarchical practical teaching mode meets the needs of students at different levels. The phased assessment in the process of practical teaching achieves the fine monitoring of the teaching process and ensures the sequential advancement of the course. The results of the curriculum reform that has been implemented for many years showed that students' practical and team cooperation abilities have significantly improved. The curriculum reform lays the foundation for the reform of other courses in the course group.

\section{Disclosure statement}

The authors declare that there is no conflict of interest.

\section{References}

[1] Ma S, Li F, Wu Z, et al., 2010, Construction and Teaching Reform of Signal and System Course Group. Journal of Higher Education Research, (3): 102-3.

[2] Li J, Guo H, Yuan H, 2016, Research on Practical Teaching of "Data Structure and Algorithm Analysis" under the Framework of Program Development Curriculum Group. Specialty and Curriculum Construction, 11.

[3] Zhang J, Fu X, 2007, The Construction of Teaching Team based on Curriculum or Curriculum Group. Teaching in Chinese Universities, (12).

[4] Lin J, 2016, How to Understand and Solve Complex Engineering Problems: Based on the Definition and Requirements of Washington Agreement. Research on Higher Engineering Education, 5. 